\title{
Monitoring the Storm Tide of Hurricane Wilma in Southwestern Florida, October 2005
}

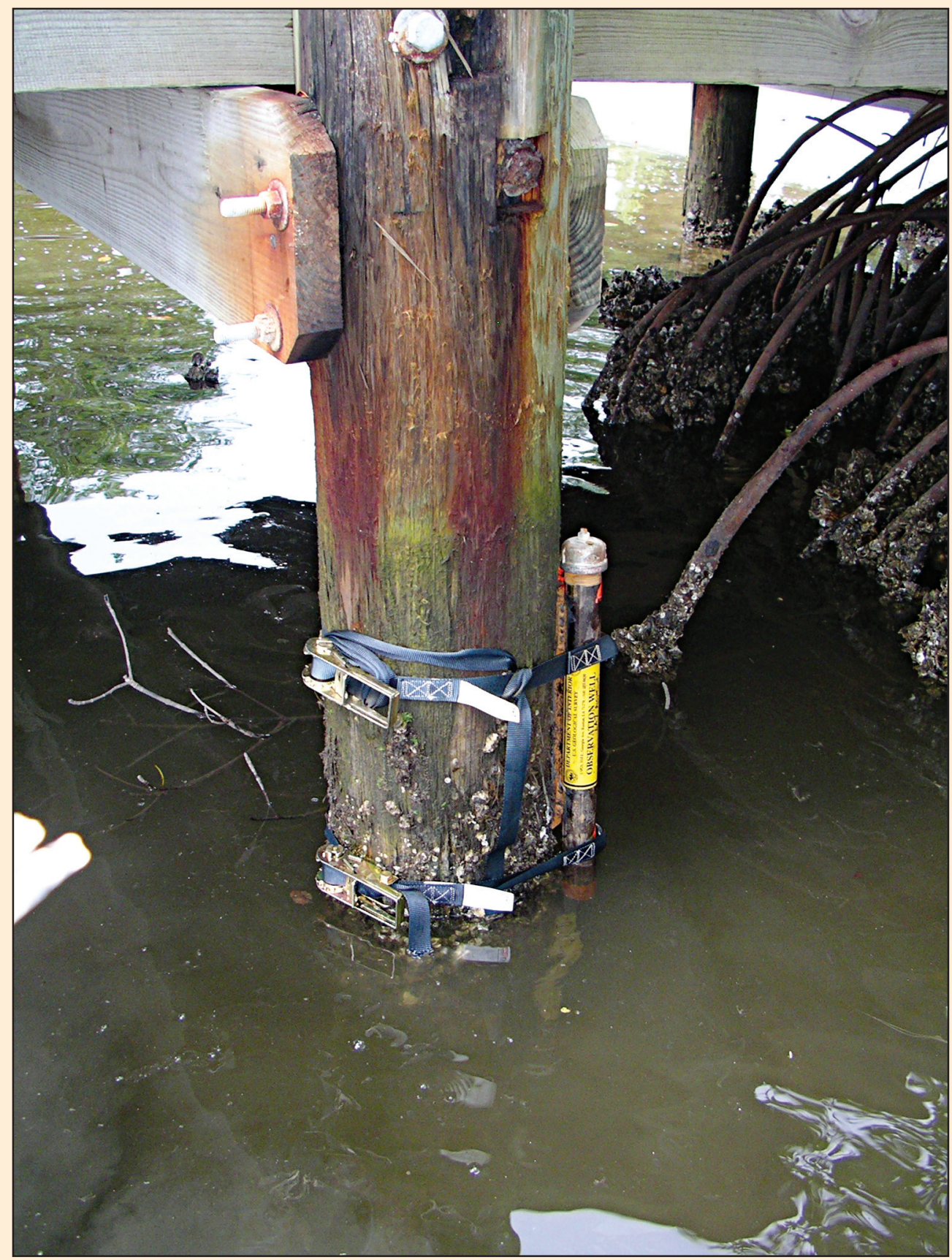

Data Series 294

U.S. Department of the Interior

U.S. Geological Survey 
